\title{
Labyrinthe
}

3 | 1999

Numéro 3

\section{Entre plaisir et désir, la parole chez Lubitsch (1932-1946)}

\section{Natacha Thiéry}

\section{(2) OpenEdition}

Journals

Édition électronique

URL : http://journals.openedition.org/labyrinthe/37

DOI : $10.4000 /$ labyrinthe.37

ISSN : 1950-6031

Éditeur

Hermann

Édition imprimée

Date de publication : 15 avril 1999

Pagination : 116-118

Référence électronique

Natacha Thiéry, «Entre plaisir et désir, la parole chez Lubitsch (1932-1946) », Labyrinthe [En ligne], 3 |

1999, mis en ligne le 20 janvier 2005, consulté le 22 septembre 2020. URL : http://

journals.openedition.org/labyrinthe/37 ; DOI : https://doi.org/10.4000/labyrinthe.37

Ce document a été généré automatiquement le 22 septembre 2020.

Propriété intellectuelle 


\title{
Entre plaisir et désir, la parole chez Lubitsch (1932-1946)
}

\author{
Natacha Thiéry
}

Ernst Lubitsch fait partie des cinéastes dont on voit et revoit volontiers les films à l'occasion des festivals réguliers et des programmations télévisuelles qui lui sont consacrés. L'intérêt intact qu'il suscite depuis les décennies qui nous séparent de la réalisation de ses sex comedies - comédies de moeurs - américaines des années 30 et 40 (The Shop around the corner, Haute Pègre, To Be or not to be, Ninotchka, Le Ciel peut attendre, Sérénade à trois, La Huitième femme de Barbe-Bleue...) témoigne de quelque chose de plus profond et de plus simple à la fois qu'une hypothétique persistance cinéphilique et mérite d'être questionné. Il faudrait certainement en chercher la raison davantage dans le rapport intime que le spectateur entretient avec ces films que dans la modernité de leur vision des rapports entre les sexes ou dans les seules trouvailles de mise en scène du cinéaste - qui sont certes remarquables et ont donné son aura à l'expression " Lubitsch touch ", cette sobriété visuelle, cette discrétion réelle ou feinte qui donnent à ses films leur spécificité.

Ce travail de recherche* ${ }^{*}$ 'est proposé de montrer dans quelle mesure ce qui séduit chez Lubitsch, la subversion, réside moins dans le discours sous-jacent de ses films que dans le sort qu'il réserve à la parole. En d'autres termes, il s'est agi de s'interroger sur la dialectique qui s'y fait jour entre le plaisir et le désir, repérables dans et par la parole, objet privilégié de cette subversion. Il faut noter que l'affinité de Lubitsch avec le théâtre - par lequel il a débuté sa carrière en 1911, dans la troupe de Max Reinhardt permet de mieux comprendre son intérêt pour la parole et ses enjeux, donc pour la mise en scène des textes en quelque sorte. Et que, dès avant les films parlants, Lubitsch jouait déjà, dans ses films muets, sur les ressources narratives de la parole, même si celle-ci était devinée ou fantasmée et non entendue : par exemple, les jeux expressifs de Pola Negri dans Madame Dubarry (1919), ou la très belle séquence du Prince étudiant (1927) au cours de laquelle Käthi (Norma Shearer) oublie le texte de son poème de bienvenue pour le prince Karl Heinrich (Ramon Navarro). Quant à son choix, à partir du début des années 30 , d'un genre unique, la comédie ${ }^{1}$, s'il répondait aux attentes du 
public donc des grands studios, il correspondait aussi à la sensibilité et à l'humour de Lubitsch, et par extension, à l'usage ludique et érotique qu 'il voulait faire de la parole et plus généralement, de la bande sonore - non seulement les dialogues mais aussi les bruits et la musique. La parole échoue souvent à faire communiquer les personnages, et informe plutôt, de manière indirecte, détournée, sur les locuteurs et leur façon de parler donc de se comporter. On se comprend souvent à demi-mots, ou à mots couverts, par mot de passe ou par allusion, ou encore par des figures comme l'antiphrase ou la litote. La parole importe souvent davantage comme signifiant que comme signifié, comme en témoignent certains jeux sonores sur les onomatopées dans de nombreux films : par exemple, les borborygmes de Jacques, le valet de Haute Pègre, les aboiements du père de Nicole à la fin de La Huitième femme de Barbe-Bleue, le hoquet intempestif de Jill Baker dans Illusions perdues... La parole devient même un objet ludique à l'origine de maints quiproquos comiques, y compris dans des circonstances extrêmement décisives où la vie peut être en péril si l'usage et le mouvement des mots ne sont pas maîtrisés (Joseph Tura dans To Be or not to be, qui se trompe de mot et trahit son identité véritable, son lapsus équivalant alors à un faux pas), circule et rebondit de l'un à l'autre, fait des tours et des détours par l'intermédiaire de relais humains ou mécaniques. Ainsi, comme un objet plus ou moins encombrant, la parole peut être confisquée à son auteur pour se voir réappropriée par un autre.

Dans ce contexte, la parole contribue également à la structuration de l'espace. Aussi la mise en scène est-elle indissociable de l'usage que l'on fait, chez Lubitsch, des mots et des sons. Ainsi, comme au théâtre, la profusion des portes va de pair avec le foisonnement de la parole. Telles des écluses, les portes régulent le flux verbal des personnages. La parole n'est pas au service de la mise en scène, c'est la mise en scène qui accompagne, souligne, exhausse la parole. C'est aussi par la parole et son devenir dans l'image - selon qu'elle se fait entendre dans le plan ou hors-champ par exemple que le cinéaste, dont on sait qu'il accorde un soin tout particulier à la qualité de ses dialogues, intègre le spectateur à sa mise en scène - qui favorise souvent le jeu des ellipses ou les écarts comiques entre la bande sonore et la bande image - et le fait participer au plaisir du texte. Il entretient avec lui une relation de connivence et de distance mêlées : il le frustre dans sa curiosité et sa participation affective au déroulement du film lorsqu'il le met littéralement à la porte, lui interdisant momentanément de voir et d'entendre, mais flatte également son narcissisme en lui adressant des clins d'œil et en stimulant son imagination et son humour.

La parole se révèle comme l'enjeu, le point névralgique des relations que nouent les personnages lubitschiens, très sensibles à l'énonciation du désir et à l'élégance du langage (The Shop around the corner). Les personnages se laissent aller à une logorrhée du désir dans laquelle le salut - amoureux - ne s'obtient que pour ceux qui, dans le contexte de relations à trois ${ }^{2}$, maîtrisent les ressorts de la parole et cultivent l'art de la formule heureuse, érotique en tant que telle. Au point que le commentaire sur la relation devient plus déterminant que la nature même de celle-ci. En outre, les mots possèdent, dans ces films, une faculté tactile qui tisse entre les personnages des liens érotiques, un contact sensuel, dans l'espace de la parole et de l'écoute. Au point que l'on refuse parfois d'entendre l'autre (Ninotchka-Greta Garbo dans le film éponyme, Nicole dans La Huitième femme de Barbe-Bleue). Le corps n'est jamais dissocié de la parole et de la voix, qui seules permettent son excitation physique. La bouche n'est pas érotique par sa morphologie mais par la teneur de la parole qu'elle émet et par le grain de la voix qui la porte, cette définition d'un son vocal, son « être voluptueux ». Ainsi, la volubilité des 
personnages lubitschiens vaut comme un indice de leur faculté de désir et de leur volonté de plaisir, tant il est vrai que la parole chez Lubitsch procure et maintient leur plaisir et, par extension, celui du spectateur. Et cela, par le rire qui, comme celui de Garbo dans Ninotchka, est l'indice d'une émotion d'ordre physique et d'une disponibilité érotique.

Chez Lubitsch, la parole jaillit là où on ne l'attend pas, crée des effets déterminants pour la poursuite de la narration et induit des attractions et des répulsions d'ordre physique. Par elle enfin, le cinéaste " parle » du dispositif cinématographique en désignant les leurres, les mensonges, les impostures magnifiques de la parole, et à travers elles, les artifices subtils de la séduction, celle des êtres les uns envers les autres comme celle du cinéma envers ses spectateurs.

\section{NOTES}

*. Mémoire de maitrise soutenu en 1996 par l'auteur sous la direction de Charles Tesson, à l'université de Paris III-Sorbonne Nouvelle.

1. Exception faite du mélodrame intitulé L'homme que j'ai tué (Broken Lullaby ou The Man I Killed) réalisé en 1932.

2. La plupart des films américains de Lubitsch furent des adaptations de pièces de théâtre. Il a repris le schéma vaudevillesque ternaire habituel, mais lui a fait subir toutes sortes de variations et de nuances dans des trios amoureux et/ou conjugaux. 